\title{
Perspective Taking Abilities among Persons with Autism: A Preliminary Study*
}

\section{Toma de perspectiva cognitiva en personas con autismo: Un estudio} piloto

Received: 19 September 2017 | Accepted: 01 March 2018

\author{
BernadetTe Rogé ${ }^{a}$ \\ Jean-Jaurès University, Francia \\ ORCID: http://orcid.org/0000-0003-0129-9545 \\ Etienne Mullet \\ Institute of Advanced Studies (EPHE), Francia \\ ORCID: http://orcid.org/0000-0002-1707-3914
}

${ }^{a}$ Correspondence author. E-mail: roge@univ-tlse2.fr

How to cite: Rogé, B., \& Mullet, E. (2019). Perspective taking abilities among persons with autism: A preliminary study. Universitas Psychologica, 18(5), 1-10. https://doi.org/10.11144/Javeriana.upsy18-5. ptap

\begin{abstract}
This preliminary study examined persons with autism's perspective taking abilities. Participants were 28 persons with autism and 27 controls. Among the persons with autism, 15 presented the Asperger Syndrome that was described in the DSM4. Scenarios in which persons were about to buy a piece of clothing were presented to participants who assessed the extent to which these persons were going to buy it as a function of suitability and price (situational factors), and what is known about their purchasing habits (the personality factor). In the same way as controls, participants with autism were able to integrate personality information into their judgments. However, only participants presenting the Asperger Syndrome described in the DSM4 were, in the same way as controls, able to vary, as a function of personality information, the importance given to situational factors during the judgment process.

Keywords

Autism Spectrum Disorder; Asperger's Syndrome; Judgment; Cognitive Perspective
\end{abstract} Taking.

\section{RESUMEN}

Este estudio piloto comparo la capacidad de toma de perspectiva de 28 personas con autismo con la de 27 personas sin autismo. Los participantes examinaron escenarios realísticos describiendo una persona que quiere comprar un vestido (a) que cuesta más o menos caro y (b) que le va muy bien o le va bien, pero sin más (factores de situación). Además, la persona que compra esta descrita como una persona que compra fácilmente o como una persona frugal (factor de personalidad). Los participantes juzgaron de la probabilidad que la persona vaya, en cada situación, a comprar el vestido. De la misma manera que los participantes sin autismo, los participantes con autismo fueron capaces de tener en cuenta la personalidad del comprador en sus juicios de probabilidad. No obstante, solo los 15 participantes con autismo que presentaban el síndrome de Asperger descrito en el DSM IV fueron, dela misma manera que los participantes sin autismo, capaces de variar el impacto, en sus juicios, de los factores de situación en función de la personalidad del comprador.

Palabras clave

Síndrome de Autismo; Síndrome de Asperger; Juicio; Toma de Perspectiva Cognitiva. 
Understanding and predicting, at least to some extent, other people's thought and behavior is indisputably an important social skill (e.g., Barnes-Holmes, Barnes-Holmes, \& McHugh, 2004). It allows positive human interactions such as collaborative work, intimate conversation, efficient teaching, and the growth of reciprocal trust and sympathy between people. It also allows pretence, deception, and abusive persuasion. Anticipating other's thought and behavior involves perspective-taking; that is, the ability "to put oneself in others' shoes" (García Pérez, Hobson, \& Lee, 2008, p. 159). While perspective-taking has been diversely defined, there is a general agreement on the view that it involves a capacity to infer other persons' emotions (e.g., anxiety) and/or cognitions (e.g., intentions) from information about themselves and their immediate environment.

Perspective taking abilities develop early (e.g., Carpenter, Nagell, \& Tomasello, 1998). Indeed, young children aged 2 already understand that other people behave as a function of their proper wishes, which can be different from their own. At age 3, they understand that people can act as a function of false beliefs about a situation. Finally, from age 5 , a majority of children seem to excel at a wide range of perspective-taking tasks (e.g., Baron-Cohen, Tager-Flusberg, \& Cohen, 2000). Although the majority of people with autism may present some delays, especially in cognitive perspective taking, there is a lack of empirical consensus about emotion recognition ability (especially basic emotions) for persons with autism (LeBlanc, Coates, Daneshvar, CharlopChristy, Morris, \& Lancaster, 2003; MacKay, Knott, \& Dunlop, 2007).

Cognitive perspective taking abilities among persons with autism have been mostly studied in situations in which participants have been given information about a situation and have to infer the thought or behavior of a person to whom information have not been communicated (e.g., the "Sally Anne task", Wimmer \& Perner, 1983, or the unexpected contents task, Gopnik \& Astington, 1988). If participants deliberately ignored information that had not been communicated to the other person at the time they infer his/her thought or behavior, they are credited with perspective taking ability. More complex situations have also been used. As an example, two persons, $\mathrm{A}$ and $\mathrm{B}$, store an object in a cupboard, and then A moves the object from the cupboard to a different cabinet while B discretely observes him/her. If participants deliberately ignored the information regarding B's awareness of the move, and state that A, who ignores that $\mathrm{B}$ was informed of the move, expects $\mathrm{B}$ to look at the cupboard (instead of looking at the cabinet) when in need of the object, they are credited with higher order perspective taking ability (Baron-Cohen, Joliffe, Mortimore, \& Robertson, 1997; Perner \& Wimmer, 1985). One issue with this kind of situations is that they assess perspective taking in conjunction with mentalizing skills.

In daily life, there are forms of cognitive perspective taking ability that does not involve mentalization. These situations only require consideration of situational factors or nonmentalizing intentionality or personality factors. They consist in inferring another person's thought and behavior in situations in which complete information is available to this person but the person is supposed to look for information and/or to interpret information in a way that is potentially different from the participant's one. Au-Yeung, Kaakinen, and Benson (2014) presented some house scenes to persons with autism and to a control group. In one condition, participants were asked to look for valuable items in the house, either from the perspective of a burglar (whose intention is to steal the more valuable items) or without any specific instruction. In a second condition, they were asked to look for features in the house that need to be fixed, either from the perspective of a repairman or without any specific instruction. Regarding eye movement measures, no difference was found between both groups in the "burglar" condition. Nevertheless, in the "repairman" condition, persons with autism were less able to look at relevant features compared to participants from the control group. Some 
perspective taking situations are thus more challenging than others for persons with autism.

\section{The Present Study}

The present, preliminary study also examined perspective taking abilities in situations in which complete information was available. It used a judgment task that was based on Wills and Moore's work (1996). This task was already employed by Ligneau and Mullet (2005) to assess perspective taking abilities among elderly people. It required consideration of situational factors or personality factors and did not required mentalization. Our main question was: Do persons with autism take into account what is known about other persons' personality for judging from these other persons' viewpoint? In other words, are persons with autism able to mimic another person's judgment process using personality information about this person?

A shopping scenario was used to assess perspective taking abilities. In this scenario, a person shops because she needs to buy a new piece of clothing. The one that she is currently considering suits her very well but it is very expensive. Will this person buy this piece of clothing? If nothing is known about this person's purchasing habits, the only two options available to participants would be (a) either to refuse to respond, and explain that without knowing this person's habits, it is not possible to infer anything about her purchasing behavior or (b) to suppose that this person is similar to themselves regarding purchasing habits and to apply one's own judgment policy. If, however, information is available regarding this person, and if he/she is known to be an extravagant consumer, then, inferring his/her purchasing behavior may be possible. An extravagant person will not attribute much weight to price and will base his/her decision mainly on suitability: The probability that he/she buys the piece of clothing should be high in the example above. In contrast, if this person is known to be thrifty, and as a thrifty person, will attribute heavy weight to price, the probability that he/she buys the piece of clothing should be low. If participants, therefore, systematically adjust their judgments regarding purchasing as a function of available information regarding this person, they can be credited with perspective taking ability.

In light of this scenario, it is possible to make our research questions more concrete. Are persons with autism able to consider that information about purchasing habits is relevant, and to take this information into account at the time of judging from the other persons' viewpoint? More concretely, are persons with autism able to change the weight they attribute to price as a function of the person' purchasing habits, giving it more weight if the person is described as thrifty and less weight it the person is described as extravagant? In technical terms, would it be possible to detect a significant Price $x$ Habits interaction?

Our hypothesis was that, when information regarding suitability, price and persons' purchasing habits are provided, participants with autism would be able to take into account suitability and price information into their judgments, but they would not be able to change to the same extent as controls, the weight attributed to price as a function of what has been indicated of the other person's general propensity to buy. The first part of this hypothesis was based on Rogé and Mullet's (2011, see also Morales \& Rogé, 2016) findings showing that in judgments tasks, persons with autism use the available information in the same way than controls of the same developmental level (except in the case of intentionality information). The second part of the hypothesis was based on previous findings showing relative impairment in cognitive perspective taking among persons with autism (Au-Yeung et al., 2014; LeBlanc et al., 2003; MacKay et al., 2007; Meyer \& Hobson, 2004).

\section{Method}

\section{Participants}

Participants were 28 persons with autism (17 children aged 8 to 14 years, 11 adolescents or 
adults aged 17 to 34 years and 27 persons of about the same chronological age without autism. They were recruited at the Regional Center for Persons with Autism's Education, Toulouse, France. The sample was a convenience sample.

\section{Table 1}

Demographic characteristics of the sample. Scores are expressed in percentiles. Values in parenthesis are standard deviations. Values with a different subscript were significantly different at $p=0.05$.

\begin{tabular}{lcccc}
\hline \multirow{2}{*}{ Characteristic } & \multicolumn{3}{c}{ Group } & \multirow{2}{*}{ Total } \\
\cline { 2 - 4 } & High Functioning & Asperger & Controls & \\
\hline Age & $15.62(8.72)$ & $17.73(8.95)$ & $16.69(8.52)$ & $16.72(8.55)$ \\
Verbal score & $31.69(32.90)^{\mathrm{a}}$ & $65.47(31.74)^{\mathrm{b}}$ & $72.26(28.16)^{\mathrm{b}}$ & $60.82(34.05)$ \\
Non-Verbal score & $43.46(19.51)^{\mathrm{a}}$ & $66.27(29.04)^{\mathrm{b}}$ & $67.59(28.02)^{\mathrm{b}}$ & $61.53(28.01)$ \\
Gender (females) & $38 \%$ & $20 \%$ & $41 \%$ & $35 \%$ \\
\hline
\end{tabular}

The diagnosis of autism was provided by a qualified psychiatrist. Among the participants with autism, all were considered as HighFunctioning (HF). In addition, using DSM4 instead of DSM5, 15 of them would have been considered as presenting what was formerly called Asperger's Syndrome (AS). The scales used were the French adaptations of the Autism Diagnostic Observation Schedule and of the Autism Diagnostic Interview (Rogé, Fombonne, Fremolle, \& Arti, 2009; Fombonne, Fremolle, \& Arti, 2010). For all participants scores to verbal (Vocabulary sub-test, Wechsler, 2005; 2011) and non-verbal (Progressive Matrix, Raven, Raven, $\&$ Court, 2003) tests were also obtained. Scores and demographic characteristics are shown in Table 1.

Written informed consent was obtained from each participant. Regarding persons with autism, authorizations from institutions to which they belonged were obtained. For participants under 18 , parental consent was solicited. Information about participants' rights (e.g., confidentiality), and study implications were carefully provided to all persons. Overall, the study protocol conforms to the scientific and ethical guidelines provided by the French Psychological Society.

\section{Material}

The material was composed of 12 scenarios describing a situation in which a person was shopping for a piece of clothing. Each of these scenarios contained three pieces of information: (a) the suitability of this piece of clothing (does not suit the person very well vs. suits the person very well), (b) the price of the piece of clothing under consideration (high, average or low), and (c) this person's purchasing habits (extravagant vs. thrifty consumer). These 12 scenarios were devised as a function of an orthogonal factorial design with three factors, Suitability $\mathrm{x}$ Price $\mathrm{x}$ Habits, $2 \times 3 \times 3$.

An example of a scenario is the following: "David needs a new skirt. David is very thrifty; he does not like to spend money without good reasons. The salesperson proposes a shirt which color is not of the kind that suits David very much. This shirt is, however, very cheap. Do you think that David is going to buy this shirt?" Responses were given on a continuous $0-10$ response scale ranging from "Sure that he will not buy it" to "Sure that he will buy it". (The complete set of scenarios is available from the authors.)

\section{Procedure}

Firstly, as recommended by Anderson (2008; 2016), the experimenter explained to each participant what was expected from him/her, in a so-called familiarization phase. The participants read out loud six stories taken randomly from the set of 12 . After each story was read, the experimenter reminded them of the critical items of information. Then, participants rated the degree to which they thought that the character in the story would buy the item. They were allowed to compare their responses and change them. As some participants were young (8-10 years), precautions were taken in order to ensure that they well understood the stories.

In a second experimental phase, the 12 stories were presented (in different order for each participant), and the participants provided their ratings. Comparing responses going back or making changes was no longer possible. Tests were completed individually and there was no time limit. 


\section{Results}

For all scenarios in the second, experimental phase, the distance was measured between the left anchor (not buy) and each answer. All subsequent analyses were based on these measures of distance. The data were analyzed, at the group level, by performing ANOVAs, and by constructing detailed graphs. The design of the first ANOVA was participant's Group (High Functioning, Asperger Syndrome, and Controls) x Suitability x Price x Habits, 3 x 2 x $3 \times 2$. Annex A shows the detailed results. Figure 2 shows the detailed effect of the four factors. The significance threshold was set at 0.05. The data met all assumptions necessary to run parametric procedures.

The Group effect was not significant. The three groups used the response scale in the same way (which greatly facilitated the interpretation of the results). Ratings were higher when the piece of clothing suited the person $(M=7.47)$, the item was cheap $(M=6.72)$, and the characters were depicted as extravagant $(\mathrm{M}=$ 5.89) than when it did not suit the person ( $M$ $=2.60)$, it was expensive $(\mathrm{M}=3.32)$ or the characters were depicted as thrifty $(M=4.18)$. The effect sizes for each of these three factors were strong (higher than .50). The two-way interactions involving the Group factor were not significant; that is, the three groups used the information in the same way. The impact of the habits factor on ratings was the same among HF, AS, and controls.

\section{Figure 1.}

Participants' ratings as a function of suitability of the piece of clothing, price, characters' purchasing habits, and group
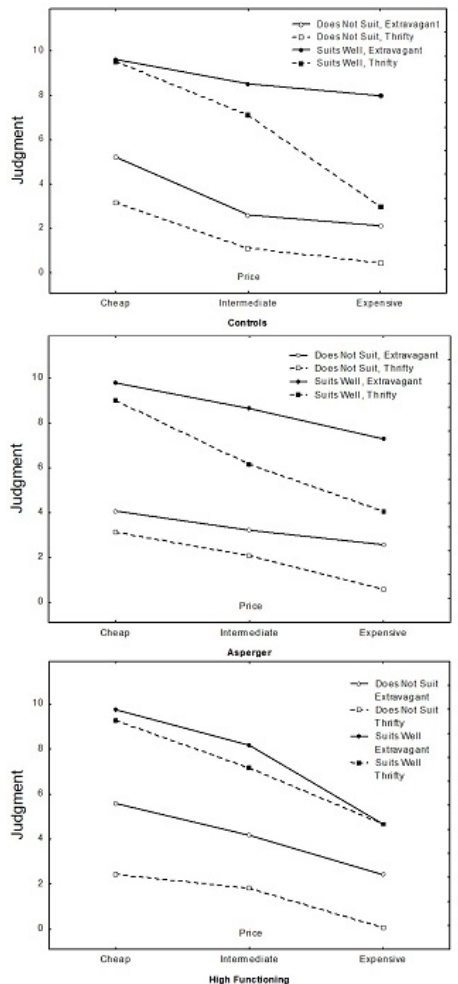

Note. Persons with high functioning autism spectrum disorder (HF), persons with Asperger's syndrome (AS), and controls. Participants' ratings are on the vertical axis. The three levels of price are on the horizontal axis. The four curves in each panel correspond to the four combinations of suitability (two levels) and character's purchasing habits (two levels). Each panel in a row corresponds to a group of participants.

The Suitability $\mathrm{x}$ Price interaction was significant. Overall, when the piece of clothing was indicated as suitable, the impact of price on ratings was stronger (a difference of 4.22 between the highest and lowest mean ratings) than when it was indicated as non suitable (a difference of 2.57). The Group x Suitability x Price interaction was, however, not significant. The variation in the impact of price on ratings, as a function of suitability, was similar in the three groups.

The Price $\mathrm{x}$ Habits, the Group $\mathrm{x}$ Price $\mathrm{x}$ Habits, and the Group $x$ Suitability $x$ Price $x$ Habits interactions were significant. Overall, the 
impact of price on ratings varied as a function of habits information: When the characters were presented as thrifty, the effect of price was stronger (a difference of 3.95) than when they were described as extravagant (a difference of 2.83). The significant three-way interaction, however, showed that this variation of the impact of price as a function of habits was observed only among controls and among AS. Among HF, the impact of price was constant. (A complementary ANOVA conducted specifically on the HF data showed that the Price $\mathrm{x}$ Suitability interaction was non-significant, $p=0.72$ ). Finally, the significant four-way interaction (see Figure 1) showed that this three-way interaction was only operative when the piece of clothing was suitable. When it was not suitable, the impact of price on ratings was always constant. Post-hoc analysis showed that (a) regarding the three-way interaction, the difference was between $\mathrm{HF}$ and both other groups, and (b) regarding the four-way interaction, the difference was between controls and both other groups.

Four other ANOVAs were conducted with an Alternative Variable $\mathrm{x}$ Suitability $\mathrm{x}$ Price $\mathrm{x}$ Habits, $3 \times 2 \times 3 \times 2$ design. Their objective was to assess that extent to which the results that have been presented above were in fact attributable to external factors such as Age (children vs. others), Gender, Verbal score, and Nonverbal score (highest vs. lowest scores). Table 1 (bottom part) shows the critical results. In no case did the critical Alternative Variable $x$ Price $x$ Habits, and Alternative Variable x Suitability x Price x Habits interactions reach significance.

\section{Discussion}

No significant difference was found between the three groups regarding the way they used the judgment scale. Consistent with Rogé and Mullet's (2011) findings, all participants understood the task at hand.

As hypothesized, participants with autism who were members of the HF group were able to take price and suitability information into account and to integrate them into their judgments, which was consistent with Rogé and Mullet's (2011) findings. In addition, these participants integrated these two pieces of information in the same interactive way as controls; that is, they were able to understand that for an item is very attractive, price must be low and suitability must be high. In other words, these participants were able to integrate information in a way that can be considered as complex: They understood that, at the time of purchasing, the price of an item was more relevant when this item was suitable than when it was not, and that the suitability of an item was more relevant when this item was cheap than when it was (too) expensive. As was not hypothesized, however, these participants were also able to take into account information about the characters' purchasing habits: Extravagant persons were considered as more likely to buy any item than thrifty persons. In addition, this information was taken into account in the same way as in controls. It can thus be concluded that HF were able of some form of cognitive perspective taking at the time of judging.

As hypothesized, participants with autism who were members of the HF group were not able to vary the impact attributed to price on judgment as a function of the characters' purchasing habits. This absence of variation of impact was not attributable to any supposed difficulty among these participants to vary the impact of pieces of information as a function of context. As stated early, they were able to vary the impact of price as a function of suitability; that is, as a function of situational information. This absence of variation was specific: These participants were not able to vary the impact of price as a function of information about the characters' personality. It can thus be concluded that if HF participants were able of cognitive perspective taking at the time of judging, this ability was bounded. They integrated the information about habits into their judgments as if it were situational information and not personality information. In other words, they were unable to alter the information integration process itself as a function of what this information implies in terms of psychological functioning. This finding was 
consistent with previous findings (e.g., Au-Yeung et al., 2014; Meyer \& Hobson, 2004).

In contrast with $\mathrm{HF}$, participants from the AS group were able to take into account information about the situation and information about characters' personality. They were also able to change the impact of one situational information .- price -. on their judgments as a function of the characters' personality .purchasing habits -- information. In other words, they understood what this information implies in terms of psychological functioning. It can be concluded that AS participants were fully able to put themselves into the characters' shoes (García Pérez, et al., 2008). This finding was consistent with views already expressed by authors such as Rogers, Dziobek, Hassenstab, Wolf, \& Convit (2007) or Krahn and Fenton (2009). Nevertheless, a small difference was found between AS and controls. Controls varied the impact of price on their judgments only in the case where the item was suitable; that is, they varied it only in the more relevant situation. AS varied the impact of price in both cases; that is, when the item was suitable and when it was not very suitable.

It must be stressed that the better performance of AS participants relatively to HF participants was not attributable to intelligence scores. When entered as a between-subject factor, IQ (higher vs. lower) did not interact with other variable in the way the Group factor interacted. Although the three groups' verbal and non-verbal scores significantly differed, observed differences in the use of information cannot be attributed to variations in intelligence scores.

\section{Limitations}

This preliminary study has limitations. Firstly, since we studied a convenience sample of persons with autism in one area of France, our findings need to be considered carefully and to be replicated using different samples and different judgment tasks.

Secondly, we used vignettes, not real situations. Even though reading vignettes is different from relating with persons, vignettes are commonly used in studying participants' judgments processes. The external validity of the method itself was found to be good by Levin, Louviere, Schepanski, and Norman (1983) and Fruchart, Rulence-Paques and Mullet (2007). In the current study, as plausible situations were presented in the vignettes, participants, even the younger ones, had little trouble in making judgments; which was an important sign of the validity of the vignettes: If the situations had been non-ecological, the judgment process would have been much more laborious for all of them. In addition, using vignettes was necessary for the following reason. We examined how cues were weighted, how they were combined, and how different categories of participants differed in weighting and combining. One condition for examining the processes of weighting and combining, independently of other processes, is that each participant has the same information presented in the same way.

Thirdly, although the chosen situation was easily understandable by all participants (and the expected main effects were found in all groups), participants differed regarding their level of familiarity with it. Young people in particular do not usually make purchasing decisions regarding anything beyond their pocket money. Many will have no experience buying stuff other than sweets or tiny toys.

\section{Implications}

The present findings are tentative but they illustrate the possible need to carefully distinguish two forms of perspective taking in judgment. The first form of perspective taking would consist in being able to use personality information (ex., the other person's habits) to alter one's judgment process, making it to conform, as far as possible, to the other person's inferred judgment process. This form would express the very essence of cognitive perspective taking. Here, situational information and personality (or intentionality) information are functionally distinguished. 
The second form would consist in being able to integrate personality information in addition to situational information without realizing that personality information is indicative of the way situational information must be used. Here, all pieces of information are attributed the same status; they are just informers. As shown above, HF were able to integrate habits information with price and suitability information. Personality information, however, did not alter the way they used situational information, despite the fact that HF were able of integration processes of the same level of complexity than the one that is implicated in the first form of perspective taking ability. In contrast, AS and controls were able to fully express the first form of perspective taking ability.

Future studies, using a full range of daily life judgment situations (e.g., buying sweets or tiny toys, going to a movie, moving to another place, refusing to take prescribed drugs), and, in each case, a full range of responses types involving cognitive aspects (e.g., in terms of likelihood to do it), motivational aspects (e.g., in terms of willingness to do it) or emotional aspects (e.g., in terms of repulsion or fear) should provide an in-depth examination of the differences in perspective-taking abilities between participants with autism and controls, and the effect of type of task on these abilities.

Future studies should also test whether participants who are only able to express the second form of perspective taking ability can be taught how to use information about persons in view of mimicking their judgment processes or, at least, in view of anticipating their responses. Bonnin-Scaon, Lafon, Chasseigne, Mullet, \& Sorum (2002), see also Liégeois, Chasseigne, Papin, \& Mullet, (2003), using the same methodology as we employed in the present study, were able to teach people, through feedback on a series of concrete cases - a technique called functional learning (Mullet, 2012), to radically change their judgment rule. One may wonder whether using this type of learning technique educators would be able to make all participants learn to mimic other persons' judgment processes.

\section{References}

Anderson, N. H. (2008). Unified social cognition. New York, NY: Psychology Press.

Anderson, N. H. (2016). Information Integration Theory: Unified Psychology based on three mathematical laws. Universitas Psychologica, 15(3), 1-7. https://doi.org/10.11144/Javeria na.upsy15-3.iitu

Au-Yeung, S. K., Kaakinen, J. K., and Benson, V. (2014). Cognitive perspectivetaking during scene perception in Autism Spectrum Disorder: Evidence from eye movements. Autism Research, 7(1), 84-93. h ttps://doi.org/10.1002/aur.1352

Barnes-Holmes, Y., Barnes-Holmes, D., \& McHugh, L. (2004). Teaching derived relational responding to young children. Journal of Early Intensive Behavior Intervention, 1(1), 3-12. https://doi.org/10.1 037/h0100275

Baron-Cohen, S., Jolliffe, T., Mortimore, C., \& Robertson, M. (1997). Another advanced test of theory of mind: evidence from very high functioning adults with autism or Asperger syndrome. Journal of Child Psychology and Psychiatry, 38, 813-822. https://doi.org/10.1111/j.1469-76 10.1997.tb01599.x

Baron-Cohen, S., Tager-Flusberg, F., \& Cohen, D. (Eds.). (2000). Understanding other minds: Perspectives from developmental cognitive neuroscience (2nd ed.). Oxford: Oxford University Press.

Bonnin-Scaon, S., Lafon, P., Chasseigne, G., Mullet, E., \& Sorum, P. C. (2002). Learning the relationship between smoking, drinking alcohol, and the risk of esophageal cancer. Health Education Research, 17(4), 415-424. https://doi.org/10.1093/her/17.4.415

Carpenter, M., Nagell, K., \& Tomasello, M. (1998). Social cognition, joint attention, and communicative competence from 9 to 15 months of age. Monographs of the Society for Research in Child Development, 63(4), 1-143. https://doi.org/10.2307/1166214

Fruchart, E., Rulence-Paques, P., \& Mullet, E. (2007). Ecological validity test of laboratory 
studies on information integration. Teorie $\mathbb{E}$ Modelli, 12(1-2), 281-288.

García Pérez, R. M., Hobson, R. P., \& Lee, A. (2008). Narrative role-taking in autism. Journal of Autism and Developmental Disorders, 38, 156-168. https://doi.org/10.1 007/s10803-007-0379-z

Gopnik, A., \& Astington, J. W. (1988). Children's understanding of representational change and its relation to the understanding of false belief and the appearance-reality distinction. Child Development, 59, 26-37. https://www.jstor.o $\mathrm{rg} / \mathrm{stable} / 1130386$

Krahn, T., \& Fenton, A. (2009). Autism, empathy and questions of moral agency. Journal for the Theory of Social Behavior, 39(2), 146-166. https://doi.org/10.1111/j.1 468-5914.2009.00402.x

LeBlanc, L. A., Coates, A. M., Daneshvar, S., Charlop-Christy, M. H., Morris, C., \& Lancaster, B. M. (2003). Using video modeling and reinforcement to teach perspective-taking skills to children with autism. Journal of Applied Behavior Analysis, 36(2), 253-257. https://doi.org/10.1901/jab a.2003.36-253

Levin, I. P., Louviere, J. J., Schepanski, A. A., \& Norman, K. L. (1983). External validity of laboratory studies of information integration. Organizational Behavior and Human Performance, 31 (2), 173-193. https: //doi.org/10.1016/0030-5073(83)90119-8

Liégeois, L. Chasseigne, G., Papin, S., \& Mullet, E. (2003). Improving high school students' understanding of potential difference in simple electric circuits. International Journal of Science Education, 25 (9), 1129-1145. http s://doi.org/10.1080/0950069022000017324

Ligneau, C., \& Mullet, E. (2005). Perpectivetaking in adults and elderly people. Journal of Experimental Psychology: Applied, 11(1), 53-60. https://doi.org/10.1037/1076-898X. 11.1 .53

MacKay, T., Knott, F., \& Dunlop, A.W. (2007). Developing social interaction and understanding in individuals with autism spectrum disorder: A groupwork intervention. Journal of Intellectual and Developmental Disability, 32 (4), 279-290. ht tps://doi.org/10.1080/13668250701689280

Meyer, J. A., \& Hobson, R. P. (2004). Orientation in relation to self and other: The case of autism. Interaction Studies, 5(2), 221-244. h ttps://doi.org/10.1075/is.5.2.04mey

Morales, G. E., \& Rogé, B. (2016). Blame attribution among people with developmental disability. Universitas Psychologica, 15(3), 1-6. https://doi.org/10.1 1144/Javeriana.upsy15-3.baap

Mullet, E. (2012). Functional learning. In N. Seel (Ed.), Encyclopedia of the science of learning. New York: Springer. https://doi.org/10.1007 /978-1-4419-1428-6_323

Perner, J., \& Wimmer, H. (1985). "John thinks that Mary thinks that...": Attribution of second-order beliefs by 5- to 10-yearold children. Journal of Experimental Child Psychology, 39, 437-471. https://doi.org/10. 1016/0022-0965(85)90051-7

Raven, J., Raven, J. C., \& Court, J. H. (2003). Manual for Raven's Progressive Matrices and Vocabulary scales. San Antonio, TX: Harcourt Assessment.

Rogé, B., \& Mullet, E. (2011). Blame and forgiveness judgments among children adolescents and adults with autism. Autism, 15(6), 702-712. https://doi.org/10.1177/13 62361310394219

Rogé, B., Fombonne, E., Fremolle, J., \& Arti, E. (2009). Adaptation française de l'ADOS: Echelle d'observation pour le diagnostic de l'autisme [French adaptation of ADOS : Autism Diagnostic Observation Schedule]. Paris: Hogrefe.

Rogé, B., Fombonne, E., Fremolle, J., \& Arti, E. (2010). Adaptation française de l'ADI$R$ : Entretien pour le diagnostic de l'autismeForme révisée [French adaptation of ADIRR: Autism Diagnostic Interview-Revised]. Paris: Hogrefe.

Rogers, K., Dziobek, I., Hassenstab, J., Wolf, O. T., \& Convit, A. (2007). Who cares? Revisiting empathy in Asperger syndrome. Journal of Autism and Developmental 
Disorders, 37, 709-715. https://doi.org/10.1 007/s10803-006-0197-8

Wechsler, D. (2005). The Wechsler intelligence scale for children ( $4^{\text {th }}$ ed.). Paris: ECPA.

Wechsler, D. (2011). The Wechsler intelligence scale for adults ( $4^{\text {th }}$ ed.). Paris: ECPA.

Wills, C. E., \& Moore, C. F. (1996). Perspective-taking judgments of medication acceptance: Inferences from relative importance about the impact and combination of information. Organizational Behavior and Human Decision Processes, 66(3), 251-267. https://doi.org/10.1006/ob hd.1996.0054

Wimmer, H., \& Perner, J. (1983). Beliefs about beliefs: Representation and the containing function of wrong beliefs in young children's understanding of deception. Cognition, 13(1), 103-128. https://doi.org/10.1016/00 10-0277(83)90004-5

\section{Apéndice}

\section{Annex A}

Results of the five ANOVAs performed on the raw data. The designs used are indicated in the left hand column. Regarding the four additional designs, only the critical interactions have been indicated.

\begin{tabular}{|c|c|c|c|c|c|c|c|}
\hline \multirow{2}{*}{ Design and Factors } & \multicolumn{2}{|c|}{ Effect } & \multicolumn{2}{|c|}{ Error } & \multirow{2}{*}{$F$} & & \multirow{2}{*}{$\mathrm{Eta}^{2} \mathrm{p}$} \\
\hline & $d f$ & MS & $d f$ & $M S$ & & & \\
\hline \multicolumn{8}{|c|}{ Group $\times$ Suitability $x$ Habits $x$ Price } \\
\hline Group (G) & 2 & 0.05 & 50 & 11.80 & 0 & 1.00 & 0.00 \\
\hline Suitability (S) & 1 & 3331.34 & 50 & 9.32 & 357.62 & 0.001 & 0.88 \\
\hline Habits $(\mathrm{H})$ & 1 & 407.06 & 50 & 6.77 & 60.10 & 0.001 & 0.55 \\
\hline Price $(\mathrm{P})$ & 2 & 540.01 & 100 & 4.82 & 111.94 & 0.001 & 0.69 \\
\hline $\mathrm{G} \times \mathrm{S}$ & 2 & 5.55 & 50 & 9.32 & 0.60 & 0.56 & 0.02 \\
\hline $\mathrm{G} \times \mathrm{H}$ & 2 & 2.79 & 50 & 6.77 & 0.41 & 0.66 & .02 \\
\hline GxP & 4 & 6.38 & 100 & 4.82 & 1.32 & 0.27 & .05 \\
\hline $\mathrm{S} \times \mathrm{H}$ & 1 & 1.18 & 50 & 5.37 & 0.22 & 0.64 & .00 \\
\hline $\mathrm{S} \times \mathrm{P}$ & 2 & 33.96 & 100 & 4.56 & 7.45 & 0.001 & .13 \\
\hline Bilinear & 1 & 63.32 & 50 & 4.69 & 13.50 & 0.001 & 0.21 \\
\hline \multirow[t]{2}{*}{$\mathrm{Hx}$} & 2 & 16.38 & 100 & 3.73 & 4.40 & 0.02 & 1.08 \\
\hline & 1 & 29.45 & 50 & 4.02 & 7.32 & 0.009 & .13 \\
\hline GxS $\times P$ & 4 & 4.03 & 100 & 4.56 & 0.88 & 0.48 & 0.03 \\
\hline $\mathrm{G} \times \mathrm{H} \times \mathrm{P}$ & 4 & 10.31 & 100 & 3.73 & 2.77 & 0.035 & 10 \\
\hline G $\times$ Bilinear & 2 & 18.38 & 50 & 4.02 & 4.57 & 0 . & .15 \\
\hline HF vs. Contr. $x$ Bilin. & 1 & 36.01 & 37 & 4.49 & 8.02 & 0.0 & 18 \\
\hline HF vs. AS x Bilin. & 1 & 18 & 24 & 4 & 5.19 & & 18 \\
\hline AS vs. Contr. $x$ Bilin. & 1 & 1.28 & 39 & 3 & 0.34 & 0.57 & 0.01 \\
\hline $\mathrm{S} \times \mathrm{H} \times \mathrm{P}$ & 2 & 17.99 & 100 & & 5.39 & 0.006 & 10 \\
\hline Trilinear & 1 & 31.81 & 50 & 3.88 & 8.19 & 0.006 & 0.14 \\
\hline $\mathrm{GxS} \times \mathrm{H} \times \mathrm{P}$ & 4 & 11.34 & 100 & 3.34 & 3.39 & 0.013 & 0.12 \\
\hline G x Trilinear & 2 & 16.54 & 50 & 3.88 & 4.26 & 0.019 & 0.15 \\
\hline \multirow{2}{*}{$\begin{array}{l}\text { HF vs. Contr. x Tril. } \\
\text { HF vs. AS x Tril. }\end{array}$} & 1 & 25.58 & 37 & 3.66 & 6.98 & 0.011 & 0.16 \\
\hline & 1 & & 24 & & 0.17 & & 0.01 \\
\hline \multirow{2}{*}{\multicolumn{8}{|c|}{$\begin{array}{l}\text { AS vs. Contr. } \times \text { Tril. } 1117.88 \\
\text { Age (A) x Suitability x Habits x Price }\end{array}$}} \\
\hline & & & & & & & \\
\hline $\mathrm{A} \times \mathrm{H} \times \mathrm{P}$ & 2 & 2.43 & 102 & 4.11 & 0.59 & 0.56 & 0.01 \\
\hline $\mathrm{A} \times \mathrm{S} \times \mathrm{H} \times \mathrm{P}$ & 2 & 0.27 & 102 & 3.75 & 0.07 & 0.93 & 0.00 \\
\hline \multicolumn{8}{|c|}{ Gender $(Z) \times$ Suitability $x$ Habits $x$ Price } \\
\hline $\mathrm{Z} \times \mathrm{H} \times \mathrm{P}$ & 2 & 1.52 & 102 & 4.13 & 0.36 & 0.70 & 0.01 \\
\hline $\mathrm{Z} \times \mathrm{S} \times \mathrm{H} \times \mathrm{P}$ & 2 & 9.26 & 102 & 3.58 & 2.58 & 0.08 & 0.04 \\
\hline \multicolumn{8}{|c|}{ Verbal Score $(V) \times$ Suitability $x$ Habits $x$ Price } \\
\hline $\mathrm{V} \times \mathrm{H} \times \mathrm{P}$ & 2 & 5.09 & 102 & 4 & 1.25 & 0.29 & 0.02 \\
\hline $\mathrm{V} \times \mathrm{S} \times \mathrm{H}$. & 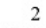 & 4.58 & 102 & & & & 002 \\
\hline \multicolumn{8}{|c|}{ Non-Verbal Score $(\mathrm{N}) \times$ Suitability $x$ Habits $\times$ Price } \\
\hline $\mathrm{N} \times \mathrm{H} \times \mathrm{P}$ & 2 & 2.33 & 102 & 4.1. & 0.57 & 0.57 & 0.01 \\
\hline $\mathrm{N} \times \mathrm{S} \times \mathrm{H} \times \mathrm{P}$ & 2 & 1.13 & 102 & 3.74 & 0.30 & 0.74 & \\
\hline
\end{tabular}

\section{Notes}

* Research article. 